\title{
Plant response to irrigation with saline water in a Sicilian vineyard: results of a three-year field investigation
}

\author{
Giuseppina Crescimanno, ${ }^{1}$ Kenneth B. Marcum, ${ }^{2}$ Francesco Morga ${ }^{1}$ \\ ${ }^{1}$ Dipartimento dei Sistemi Agro-Ambientali, Università di Palermo, Italy; ${ }^{2}$ Department of Arid land \\ Agriculture, United Arab Emirates University, Al Ain, United Arab Emirates
}

\begin{abstract}
This paper reports the results of a three-year field investigation carried out in a vineyard located in Sicily (Mazara del Vallo, Trapani) within the framework of the Project: Evolution of cropping systems as affected by climate change (CLIMESCO). Research investigated soil-plant response to irrigation performed with water having two different salinity levels; soil hydrological characteristics, soil salinity, crop transpiration and stomatal conductance were measured in field plots. The results proved that crop transpiration and stomatal conductance were significantly affected by soil salinity conditions (expressed as electrical conductivity of the soil saturated water extract). A significant reduction in both the physiological parameters was observed in the treatment irrigated with water having higher salinity (electrical conductivity equal to $1.6 \mathrm{dS} \mathrm{m}^{-1}$ ) as compared to the treatment irrigated with water of lower salinity (electrical conductivity equal to $0.6 \mathrm{dS} \mathrm{m}^{-1}$ ).
\end{abstract}

\section{Introduction}

Many Mediterranean countries, including Egypt, Libya, Tunisia, Algeria, Morocco, Syria, Malta and Lebanon exhibit water availability below the threshold of $1000 \mathrm{~m}^{3} /$ person/year. Water demands for irrigation are projected to rise, bringing increased competition between agriculture and other users (Crescimanno and Marcum, 2009). Therefore, the use of

Correspondence: Prof. Giuseppina Crescimanno, Università di Palermo, Dipartimento dei Sistemi Agro-Ambientali, viale delle Scienze 13, 90128 Palermo, Italy. Tel. +39.091 .23862201 - Fax: +39.091 .484035 .

E-mail: giuseppa.crescimanno@unipa.it

Key words: salinity, stomatal conductance, transpiration.

Acknowledgements: this research was funded by CLIMESCO Evolution of cropping systems as affected by climate change project, contract n. 285, 20/02/2006 (Ministry for Education, University and Research).

Received for publication: 6 May 2011.

Accepted for publication: 23 January 2012.

(C) Copyright G. Crescimanno et al., 2012

Licensee PAGEPress, Italy

Italian Journal of Agronomy 2012; 7:e11

doi:10.4081/ija.2012.e11

This article is distributed under the terms of the Creative Commons Attribution Noncommercial License (by-nc 3.0) which permits any noncommercial use, distribution, and reproduction in any medium, provided the original author(s) and source are credited. lower-quality sources, such as saline waters, will inevitably be practiced for irrigation purposes in order to maintain an economically viable agriculture (Crescimanno, 2001). Sicily is a typical Mediterranean country in which conditions of water scarcity and drought, as well as increasing use of saline water for irrigation are taking place (Crescimanno, 2009). In Sicily, wine grape (Vitis vinifera $\mathrm{L}$.) is one of the most important crops, both in terms of crop production and economic value. Management options suitable to prevent salinization, while maintaining acceptable levels of crop productivity and/or wine quality in irrigated vineyards, need to be developed in Sicily (Crescimanno and Garofalo, 2005; 2006). This paper reports results of a three-year field investigation carried out in a vineyard located in Sicily (Mazara del Vallo, Trapani) within the framework of the Project: Evolution of cropping systems as affected by climate change (CLIMESCO), funded by three Italian Ministries (University, Agriculture, and Environment). Research was aimed at investigating soil-plant responses to irrigation with water having two different salinity levels.

\section{Materials and methods}

Different irrigation treatments were applied to two contiguous plot, $\mathrm{L}$ and $\mathrm{R}$ respectively, at the Foraci Farm, a vineyard located in the Mazaro basin, region of Sicily, to monitor soil and plant responses to brackish irrigation water, measured in terms of electrical conductivity $\left(\mathrm{EC}_{\mathrm{w}}\right)$. In treatment $\mathrm{L}$, irrigation water came from a lake having $\mathrm{EC}_{\mathrm{w}}=1.6 \mathrm{dS} \mathrm{m}^{-1}$ while in treatment $\mathrm{R}$, water was drawn from a well having $\mathrm{EC}_{\mathrm{w}}=0.6 \mathrm{dS} \mathrm{m}^{-1}$. Two vine rows were chosen in each of the two plot and eleven, equally spaced spots were selected along each of the two rows in order to carry out measurements on soil hydraulic and plant physiological parameters. Undisturbed soil samples were taken at the selected locations to determine the soil shrinkage curve, i.e. the relationship between specific volume and gravimetric water content, and the water retention curve, i.e. the relationship between volumetric water content and matric potential. The soil shrinkage curve was necessary in order to incorporate changes in volume into the volumetric water content (Crescimanno and Provenzano,1999). The soil hydraulic parameters were determined by the parameter estimation method based on multi-step outflow experiments representing the soil water retention by the Brutsaert equation (Crescimanno and Garofalo, 2005).

Soil gravimetric water content (U), soil salinity (expressed in terms of electrical conductivity of soil saturated water extract, $\mathrm{EC}_{\text {sat }}$ ) and plant physiological measurements (transpiration and stomatal conductance) were determined on a total of the eleven spots per row. Soil saturated water extracts were prepared with soil samples collected at $60 \mathrm{~cm}$ of depth; ECsat was measured using a conductivimeter (Crison, Micro CM 2002) (Rhoades, 1993). Irrigation scheduling was performed according to the water balance methodological approach, taking into account 
meteorological data, maximum crop available water $\left(\mathrm{AW}_{\max }\right)$ and crop maximum evapotranspiration. Reference evapotranspiration (ETo) was calculated using the Hargreaves equation (Hargreaves and Samani, 1982). The amount of water supplied at each irrigation was determined by a water balance approach based on the Rijtema water availability concept (Doorenbos and Kassam, 1979); however, since a deficit irrigation is practiced in the farm to obtain a good wine quality, the soil water content was allowed to reach values close to wilting point before irrigation was applied. In addition, according to the $\mathrm{p}$ fraction $(\mathrm{P}=0.5)$ adopted to determine the irrigation scheduling, a 50\% fraction of the maximum available water was considered to allow the condition of actual evapotranspiration equal to maximum evapotranspiration. Irrigation (both in $\mathrm{R}$ and $\mathrm{L}$ rows) was performed in June and July of each year (with 3, 5 and 3 watering in 2007, 2008 and 2009, respectively). Physiological measurements were carried out the day after each irrigation. Crop transpiration $\left(\mathrm{T}_{\mathrm{r}}\right)$ and stomatal conductance $\left(\mathrm{G}_{\mathrm{s}}\right)$ were determined on three fully expanded leaves on each plant, using a CIRAS-2 portable infrared gas analyzer (PP-Systems).

\section{Results and discussion}

Table 1 reports the physical characteristics of some soil profiles (E, F, $\mathrm{G}$ and $\mathrm{H}$ ) located along the $\mathrm{L}$ and $\mathrm{R}$ rows. The four profiles were classified as typic chromoxerert and no significant differences were found between them in terms of soil texture. These soil profiles were selected for hydraulic characterization and considered representatives due to soil homogeneity in terms of physical properties. Table 2 reports the Brutsaert water retention parameters (Crescimanno and Garofalo, 2005) obtained for the same eleven soil locations (in $R$ and $L$ rows) together with the AWmax values, calculated as the difference between field capacity ( $\theta$ value corresponding to the matric potential of $102 \mathrm{~cm}$ ),

Table 1. Physical properties of the E, F, G and $\mathrm{H}$ profiles.

\begin{tabular}{lccc} 
Soil profile & $\begin{array}{c}\text { Clay } \\
(\%)\end{array}$ & $\begin{array}{c}\text { Silt } \\
(\%)\end{array}$ & $\begin{array}{c}\text { Sand } \\
(\%)\end{array}$ \\
E (R) & 55 & 37 & 9 \\
F (R) & 54 & 36 & 10 \\
\hline G (L) & 52 & 37 & 11 \\
H (L) & 33 & 34 & 33 \\
\hline
\end{tabular}

and wilting point $(\theta \mathrm{r}$, i.e. value corresponding to the matric potential of $15300 \mathrm{~cm}$ ). Statistical analysis (paired $t$-test) proved that differences between AWmax values measured in $\mathrm{L}$ and $\mathrm{R}$ rows were non-significant $(\mathrm{P}<0.01)$. The same result was obtained with reference to $\theta$ r. The two rows, therefore, had a similar hydrological behaviour in terms of amount of water retained by the soil and made available to the crop. However, the non-significantly different higher $\theta$ s values measured in the $\mathrm{L}$ row might be a consequence of soil swelling determined by the higher salinity. Figure 1 illustrates differences between the $\mathrm{EC}_{\text {sat }}$ values measured in $\mathrm{L}$ row and the $\mathrm{EC}_{\text {sat }}$ measured in the $\mathrm{R}$ row in the course of the three-year irrigation seasons. Significantly higher $\mathrm{EC}_{\text {sat }}$ values were measured in the L row compared to the R row across all three years, consistently with the higher salinity of the water used to irrigate the L row. However, from the beginning to the end of the experiment $\mathrm{EC}_{\text {sat }}$ decreased from 1.43 to $1.23 \mathrm{dS} \mathrm{m}^{-1}$ in the $\mathrm{R}$ row, and from 1.51 to 1.34 $\mathrm{dS} \mathrm{m} \mathrm{m}^{-1}$ in the $\mathrm{L}$ row. This indicated that winter rainfall was sufficient to leach the excess of salts out of the topsoil, preventing soil salinization. Figure 2 illustrates transpiration $\left(\mathrm{T}_{\mathrm{r}}\right)$ values $\left(\mathrm{mmol} \mathrm{m}^{-2} \mathrm{~s}^{-1}\right)$ measured on the eleven plants located along the $L$ and $R$ rows from 2007 to 2009. A paired t-test was carried out to evaluate the effect of the two different irrigation treatments (saline water vs non saline water) on the plants. This kind of test is advisable when differences between homogenous elements subjected to different treatments need to be evaluated. Significantly higher $\mathrm{T}_{\mathrm{r}}$ values were measured in $\mathrm{R}$ row compared to values measured in $\mathrm{L}$ row, across all the 3 sampling years $(\mathrm{P}<0.01)$. Higher

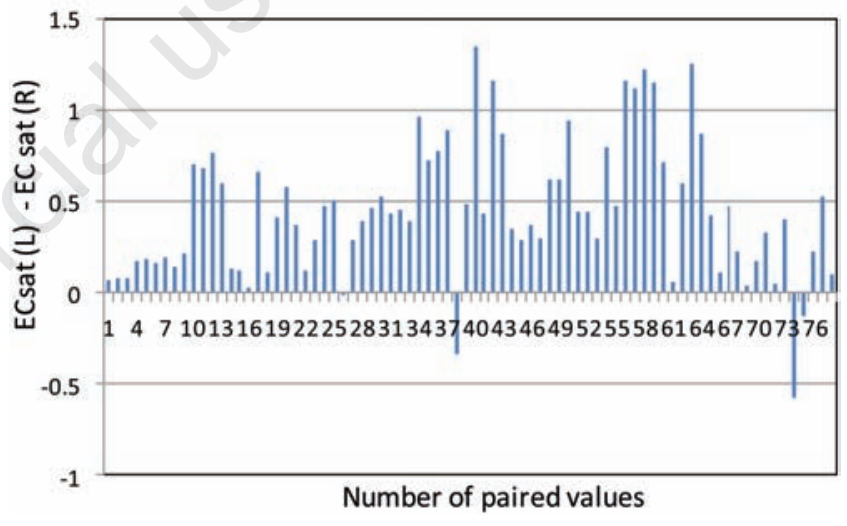

Figure 1. Difference between Electrical conductivity $\left(\mathrm{EC}_{\text {sat }}\right)$ measured $\left(\mathrm{dS} \mathrm{m}^{-1}\right)$ in the eleven paired locations along the $\mathrm{L}$ and $\mathrm{R}$ rows after irrigation at the depth of $60 \mathrm{~cm}$ (from 2007 to 2009).

Table 2. Parameters of the water retention curves determined at the eleven soil locations along the $L$ and $R$ rows and values of the maximum water available $\left(\mathrm{AW}_{\max }\right)$.

\begin{tabular}{|c|c|c|c|c|c|c|c|c|c|c|}
\hline \multirow[b]{2}{*}{ Plant $n}$. & \multicolumn{5}{|c|}{ L row } & \multicolumn{5}{|c|}{ R row } \\
\hline & $\begin{array}{c}\mathrm{AW}_{\max } \\
\left(\mathrm{cm}^{3} / \mathrm{cm}^{3}\right)\end{array}$ & $\begin{array}{c}\theta \mathrm{r} \\
\left(\mathrm{cm}^{3} / \mathrm{cm}^{3}\right)\end{array}$ & $\begin{array}{c}\theta \mathrm{s} \\
\left(\mathrm{cm}^{3} / \mathrm{cm}^{3}\right)\end{array}$ & $\alpha$ & n & $\begin{array}{c}\mathrm{AW}_{\max } \\
\left(\mathrm{cm}^{3} / \mathrm{cm}^{3}\right)\end{array}$ & $\begin{array}{c}\theta \mathrm{r} \\
\left(\mathrm{cm}^{3} / \mathrm{cm}^{3}\right)\end{array}$ & $\begin{array}{c}\theta \mathrm{s} \\
\left(\mathrm{cm}^{3} / \mathrm{cm}^{3}\right)\end{array}$ & $\alpha$ & n \\
\hline 1 & 42.0 & 0.276 & 0.501 & 0.0325 & 1.052 & 39.0 & 0.27 & 0.42 & 0.0207 & 1.005 \\
\hline 2 & 48.0 & 0.282 & 0.500 & 0.0238 & 1.005 & 36.0 & 0.27 & 0.43 & 0.0172 & 1.005 \\
\hline 3 & 42.0 & 0.281 & 0.519 & 0.0275 & 1.005 & 42.0 & 0.27 & 0.47 & 0.0217 & 1.005 \\
\hline 4 & 48.0 & 0.312 & 0.533 & 0.0254 & 1.005 & 42.0 & 0.27 & 0.47 & 0.0198 & 1.005 \\
\hline 5 & 36.0 & 0.297 & 0.523 & 0.0335 & 1.005 & 42.0 & 0.28 & 0.49 & 0.0286 & 1.005 \\
\hline 6 & 28.8 & 0.304 & 0.491 & 0.0252 & 1.197 & 42.0 & 0.28 & 0.44 & 0.0140 & 1.005 \\
\hline 7 & 42.0 & 0.293 & 0.501 & 0.0242 & 1.005 & 42.0 & 0.29 & 0.47 & 0.0191 & 1.005 \\
\hline 8 & 36.0 & 0.294 & 0.500 & 0.0262 & 1.005 & 42.0 & 0.29 & 0.48 & 0.0226 & 1.005 \\
\hline 9 & 54.0 & 0.281 & 0.520 & 0.0221 & 1.005 & 36.0 & 0.29 & 0.46 & 0.0274 & 1.005 \\
\hline 10 & 60.0 & 0.272 & 0.534 & 0.0082 & 1.334 & 42.0 & 0.29 & 0.45 & 0.0143 & 1.005 \\
\hline 11 & 42.0 & 0.315 & 0.494 & 0.0217 & 1.005 & 66.0 & 0.28 & 0.50 & 0.0093 & 1.005 \\
\hline
\end{tabular}


$\mathrm{T}_{\mathrm{r}}$ values measured in $\mathrm{R}$ indicate that greater water uptake occurred.

Figure 3 illustrates $G_{s}$ values, obtained similarly to $T_{r}$ values. Significantly $(\mathrm{P}<0.01)$ higher $\mathrm{G}_{\mathrm{s}}$ values, consistent with the higher $\mathrm{T}_{\mathrm{r}}$, were measured in the $\mathrm{R}$ row compared to values measured in the $\mathrm{L}$ row across all the three sampling years. Figure 4 illustrates the relationships of $\operatorname{Tr}$ as a function of $\mathrm{G}_{\mathrm{s}}$ according to an exponential function ( $\mathrm{y}=\mathrm{a}$ *ln $\mathrm{x}+\mathrm{b}$ ).The exponential equation selected for regressing $\operatorname{Tr} v s$ Gs adequately represented the physical process of transpiration as depending on stomatal conductance. A higher regression coefficient $\left(R^{2}\right)$, indicating a closer correlation between $\mathrm{T}_{\mathrm{r}}$ and $\mathrm{G}_{\mathrm{s}}$, was found for the R measure-

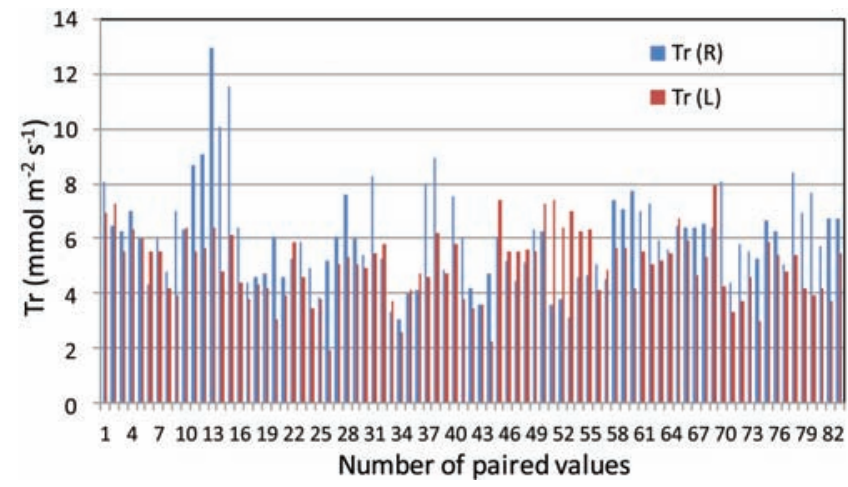

Figure 2. Transpiration $\left(T_{\mathrm{r}}\right)$ (paired values) measured after irrigation events in the eleven locations along the $L$ and $R$ rows from 2007 to 2009.

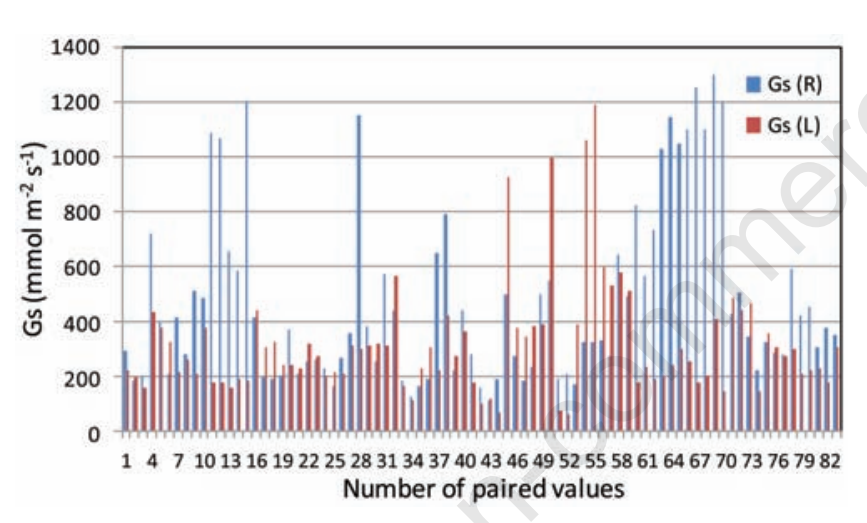

Figure 3. Stomatal conductance $\left(\mathrm{G}_{\mathrm{s}}\right)$ (paired values) measured after irrigation events in the eleven locations along the $R$ and $L$ rows (from 2007 to 2009 ).

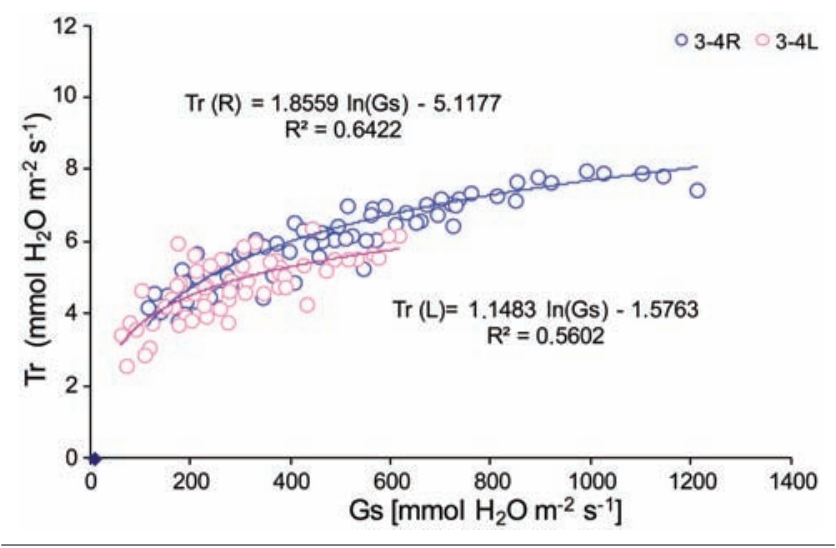

Figure 4. Relationship between $T_{r}$ and $G_{s}(R$ and $L$ rows) and fitting equations. ments compared to the L. This result indicated a stronger and more direct dependence of $T_{r}$ on $G_{s}$ in the R plants. It is interesting to notice that the $\mathrm{L}$ and $\mathrm{R}$ plants had a similar behaviour within a certain $\mathrm{G}_{\mathrm{s}}$ range $\left(\mathrm{G}_{\mathrm{s}}\right.$ values lower than $600 \mathrm{mmol} \mathrm{m} \mathrm{m}^{-2} \mathrm{~s}^{-1}$ ). The Gs values and the corresponding $\mathrm{T}_{\mathrm{r}}$ measured in the $\mathrm{R}$ row extended over a much wider range than those measured in the $\mathrm{L}$ row, reaching $\mathrm{G}_{\mathrm{s}}$ values up to $1200 \mathrm{mmol}$ $\mathrm{m}^{-2} \mathrm{~s}^{-1}$, which did not occur for the $\mathrm{L}$ plants. This indicates that some constraint occurred in the $\mathrm{L}$ plants limiting stomatal conductance and related transpiration rate within a certain range, probably because of an osmotic component which determined a lower total water potential in the $\mathrm{L}$ plants compared to the $\mathrm{R}$ plants. This plant behaviour was found to be consistent with the higher soil salinity occurring and measured in the $\mathrm{L}$ plot, confirming that soil salinity reduced the transpiration process and the stomatal conductance in the L plot compared to the R plot.

\section{Conclusions}

Results from this investigation demonstrated that crop transpiration $\left(\mathrm{T}_{\mathrm{r}}\right)$ and stomatal conductance $\left(\mathrm{G}_{\mathrm{s}}\right)$ measured in grapevines irrigated with water of different salinity were significantly affected by soil salinity conditions, expressed by electrical conductivity of soil saturated extract. Significant reductions in Tr and Gs were measured in plants in the treatment irrigated with water having $\mathrm{EC}_{\text {sat }}=1.6 \mathrm{dS} \mathrm{m}^{-1}$ (L row) compared to $\mathrm{T}_{\mathrm{r}}$ and $\mathrm{G}_{\mathrm{s}}$ values measured in plants irrigated with water having a salinity of $0.6 \mathrm{dS} \mathrm{m}^{-1}$ ( $\mathrm{R} \mathrm{row}$ ). The investigation therefore indicated that a value of ECsat $=1.5 \mathrm{dS} \mathrm{m}^{-1}$ ), discriminated a different plant response to salinity between $\mathrm{L}$ and $\mathrm{R}$ rows, supporting the salinity threshold for grapes proposed by Maas (1990). Under the irrigation conditions investigated in the Foraci vineyard, it is therefore suggested to implement management strategies aimed at keeping soil salinity under this threshold value. This objective could be realised by irrigation performed using the lower salinity water only, or by alternating the two irrigation waters.

\section{References}

Crescimanno G, 2001. Irrigation practices affecting land degradation in Sicily. Ph.D Diss., Wageningen University, The Netherlands.

Crescimanno G, 2009. Irrigation, salinization and desertification in Sicily. In: G. Crescimanno and K.B. Marcum (eds.) Irrigation, salinization and desertification. Evolution of cropping systems as affected by climate change. Aracne Ed., Roma, Italy.

Crescimanno G, Provenzano G, 1999. Soil shrinkage characteristic in clay soils: measurement and prediction. Soil Sci. Soc. Am. J. 63:25-32.

Crescimanno G, Garofalo P, 2005. Application and evaluation of the SWAP model for simulating water and solute transport in a cracking clay soil. Soil Sci. Soc. Am. J. 69:1943-1954.

Crescimanno G, Garofalo P, 2006. Management scenarios optimizing irrigation with saline water in cracking clay soils. Soil Sci. Soc. Am. J. 70:1774-1787.

Crescimanno G, Marcum KB, 2009. Irrigation, salinization and desertification. Evolution of cropping systems as affected by climate change. Aracne Ed., Roma, Italy.

Kassam AH, 1979. Yield response to water. Land and Water Development Div., FA0 Publ., Roma, Italy.

Hargreaves GH, Samani ZA, 1982. Estimating potential evapotranspiration. J. Irrig. Drain E.-ASCE 108:225-230.

Maas EV, 1990. Crop salt tolerance. In: K.K. Tanji (ed.) Agricultural salinity assessment and management. ASCE Manuals and Reports on Engineering No 71. ASCE Publ., New York, NY, USA, pp 262-304. 